\title{
Erbium in crystal silicon: Optical activation, excitation, and concentration limits
}

\author{
A. Polman, G. N. van den Hoven, J. S. Custer, ${ }^{\text {a) }}$ J. H. Shin, and R. Serna \\ FOM-Institute for Atomic and Molecular Physics, Kruislaan 407, 1098 SJ Amsterdam. The Netherlands \\ P. F. A. Alkemade \\ DIMES/CST, Delft University of Technology, Lorentzweg I, 2628 CJ Delft, The Netherlands
}

(Received 14 July 1994; accepted for publication 18 October 1994)

\begin{abstract}
The optical activation, excitation, and concentration limits of erbium in crystal $\mathrm{Si}$ are studied. Preamorphized surface layers of Czochralski-grown $(\mathrm{Cz}) \mathrm{Si}(100)$, containing $1.7 \times 10^{18} \mathrm{O} / \mathrm{cm}^{3}$, were implanted with $250 \mathrm{keV} \mathrm{Er}$ at fluences in the range $8 \times 10^{11}-8 \times 10^{14} \mathrm{~cm}^{-2}$. After thermal solid-phase epitaxy of the Er-doped amorphous layers at $600{ }^{\circ} \mathrm{C}, \mathrm{Er}$ is trapped in the crystal at concentrations ranging from $3 \times 10^{16}$ to $7 \times 10^{19} \mathrm{Er} / \mathrm{cm}^{3}$, as measured by secondary-ion-mass spectrometry. Photoluminescence spectra taken at $77 \mathrm{~K}$ show the characteristic $\mathrm{Er}^{3+}$ intra- $4 f$ luminescence at $1.54 \mu \mathrm{m}$. Photoluminescence excitation spectroscopy shows that Er is excited through a photocarrier-mediated process. Rapid thermal annealing at $1000^{\circ} \mathrm{C}$ for $15 \mathrm{~s}$ increases the luminescence intensity, mainly due to an increase in minority-carrier lifetime, which enhances the excitation efficiency. Luminescent $\mathrm{Er}$ forms clusters with oxygen: the maximum Er concentration that can be optically activated is determined by the $\mathrm{O}$ content, and is $(3 \pm 1) \times 10^{17} \mathrm{Er} / \mathrm{cm}^{3}$ in $\mathrm{Cz}-\mathrm{Si}$. The internal quantum efficiency for electrical excitation of $\mathrm{Er}$ in $\mathrm{Cz}-\mathrm{Si}$ is larger than $3 \times 10^{-6}$.

(C) 1995 American Institute of Physics.
\end{abstract}

\section{INTRODUCTION}

Erbium doping of silicon has recently become an extensively studied subject. The rare earth erbium, when incorporated in Si in the trivalent charge state, shows characteristic luminescence from an intra- $4 f$ transition at a wavelength of $1.54 \mu \mathrm{m}$. This emission can be observed both under optical or electrical excitation. This optical doping technique seems to be a promising way around the problem of the indirect band gap, which precludes efficient light emission from pure crystal $\mathrm{Si}$. If sufficiently high $\mathrm{Er}$ concentrations could be incorporated and activated in crystal $\mathrm{Si}$, it would become possible to fabricate light emitting diodes, lasers, or optical amplifiers, based on silicon. This would enable the integration of optical and electronic technologies on the same chip.

Erbium doping of $\mathrm{Si}$ was introduced by Ennen et al., who incorporated Er into crystal $\mathrm{Si}(c-\mathrm{Si})$ using $\mathrm{Er}$ ion implantation during $\mathrm{Si}$ molecular-beam epitaxy. ${ }^{1,2}$ Subsequent studies have addressed the enhancement of the Er luminescence efficiency in Si by the addition of impurities, ${ }^{3,4}$ the optical $^{5,6}$ and electrical ${ }^{7-9}$ characteristics of $\mathrm{Er}$ in $\mathrm{Si}$, and the structural aspects associated with the incorporation of $\mathrm{Er}$ in $\mathrm{Si}^{10-18}$ Recent work has focused on the attainment of roomtemperature photoluminescence (PL) from Er-doped Si. It was found that the addition of oxygen to Er-doped Si enhances the concentration of luminescent $\mathrm{Er}$, and reduces the quenching of the PL at elevated temperatures. ${ }^{19}$ As a result, room-temperature $\mathrm{PL}$ from $\mathrm{Er}$ and $\mathrm{O}$ co-doped $\mathrm{Si}$ has been observed. Ion implantation, $3,4,9$ chemical-vapor deposition, ${ }^{20.21}$ and molecular-beam epitaxy ${ }^{22}$ have been used to fabricate such $\mathrm{Er}$ and $\mathrm{O}$ co-doped samples. Most recently, it was found that $\mathrm{Er}$ and $\mathrm{O}$ co-doped $\mathrm{Si} p-n$ diodes

a) Present address: Sandia National Labs, M/S 1056, Albuquerque, NM 87185 . show room-temperature electroluminescence at 1.54 $\mu \mathrm{m} .^{23-25}$ However, up to now the luminescence intensities and quantum efficiencies obtained for $\mathrm{Er}$ in $\mathrm{Si}$ are still quite small.

The attainment of efficient luminescence from $\mathrm{Er}$ in $\mathrm{Si}$ requires four factors: (1) High concentrations of Er must be incorporated in the crystal; (2) the Fr must be incorporated in an optically active (luminescent at $1.54 \mu \mathrm{m}$ ) configuration; (3) the luminescence efficiency (lifetime) must be high; and (4) the Er must be efficiently excited.

In order to improve the emission from $\mathrm{Er}$ in $\mathrm{Si}$ these fundamental issues all need to be addressed. Recently, we have shown that Er concentrations as high as $2 \times 10^{20} \mathrm{Er} / \mathrm{cm}^{3}$ can be incorporated into $c-\mathrm{Si}^{13,18}$ This was done using highdose Er implantation into $c-S i$, which causes amorphization of the implanted surface layer. The Er-doped amorphous ( $a$ Si) layer was then recrystallized using thermal solid-phase epitaxial recrystallization at relatively low temperatures $\left(500-600^{\circ} \mathrm{C}\right)$. During regrowth, Er was segregated at the moving $a-\mathrm{Si} / c-\mathrm{Si}$ interface and trapped in the growing crystal. The details of the segregation and trapping behavior are described in Ref. 18. The attainment of such high Er concentrations fulfills the first requirement mentioned above.

In this article we address the other three requirements. The annealing characteristics of these highly Er-doped Si films are studied, with the aim to obtain maximum photoluminescence at $1.54 \mu \mathrm{m}$. Changes in the Er PL intensity are described in terms of Er active fraction, Er luminescence lifetime, and carrier lifetime in the crystal. Furthermore, measurements are shown of Er PL intensity as a function of Er concentration. It is concluded that the maximum Er concentration that can be optically activated in Czochralskigrown $(\mathrm{Cz}) \mathrm{Si}$ is $(3 \pm 1) \times 10^{17} \mathrm{Er} / \mathrm{cm}^{3}$. Possible configura- 
tions of $\mathrm{Er}$ in $\mathrm{Si}$ are discussed, as well as quantum efficiencies for electrical excitation of Er.

\section{EXPERIMENT}

Ion implantation was performed with a $1 \mathrm{MV}$ Van de Graaff accelerator, using a sputter ion source with an Er metal cathode. All implants were performed with the samples kept at $77 \mathrm{~K}$. Cz-grown (100)Si wafers were used to make two sets of samples. The first set was made by direct $\mathrm{Er}$ implantation into $\mathrm{Si}(100)(n$-type, $1-30 \Omega \mathrm{cm}$ ) at $250 \mathrm{keV}$ to a fluence of $9 \times 10^{14} \mathrm{Er} / \mathrm{cm}^{2}$. After solid-phase-epitaxial (SPE) recrystallization of the implantation-amorphized surface layer at $600{ }^{\circ} \mathrm{C}(15 \mathrm{~min}), 65 \%$ of the $\mathrm{Er}$ was trapped in the crystal to a maximum concentration of $9 \times 10^{19} \mathrm{~cm}^{-3}$, as measured using Rutherford backscattering spectrometry (RBS). ${ }^{13,18}$ Subsequent thermal annealing in the temperature range $600-1300^{\circ} \mathrm{C}$ was applied to these samples in a rapid thermal annealing (RTA) furnace under flowing $\Lambda \mathrm{r}$. The second set was made by $\mathrm{Er}$ implantation into $\mathrm{Cz}-\mathrm{Si}$ samples which were first amorphized using a $350 \mathrm{keV}, 3 \times 10^{15} \mathrm{Si} / \mathrm{cm}^{2}$ implant. Erbium was then implanted at $250 \mathrm{keV}$ into the amorphized films at fluences of $8 \times 10^{11}, 8 \times 10^{12}, 8 \times 10^{13}$, or $8 \times 10^{14} \mathrm{Er} / \mathrm{cm}^{2}$. Following the implants, the films were recrystallized at $600^{\circ} \mathrm{C}(15 \mathrm{~min})$ and subsequently annealed in the RTA at $1000^{\circ} \mathrm{C}$ under flowing $\mathrm{N}_{2}$. After annealing, the Er concentration profiles as a function of depth were determined with secondary-ion-mass spectrometry (SIMS) using $6 \mathrm{keV} \mathrm{O}{ }_{2}^{+}$sputtering. All secondary-ion intensities were converted into atomic densities using known relative sensitivity factors. ${ }^{26}$ The $\mathrm{O}$ content in the $\mathrm{Cz}$-Si wafers in this study was determined with SIMS using $16 \mathrm{keV} \mathrm{Cs}^{+}$sputtering, and was found to be $(1.7 \pm 0.5) \times 10^{18} \mathrm{O} / \mathrm{cm}^{3}$.

PL spectroscopy was performed using the $514.5 \mathrm{~nm}$ line of an Ar laser as a pump source. The light beam was focused to a 1-mm-diam spot on the sample. The $1 / e$ penetration depth at this wavelength is $890 \mathrm{~nm}$ in $c-\mathrm{Si}^{27}$ For most measurements the pump power at the sample was fixed at 160 $\mathrm{mW}$. The pump beam was mechanically chopped at $55 \mathrm{~Hz}$. The luminescence signal was collected using a $48 \mathrm{~cm}$ monochromator, a liquid-nitrogen-cooled $\mathrm{Ge}$ detector, and a lock-in amplifier. The spectral resolution was $6 \mathrm{~nm}$. All PL measurements were performed using a liquid-nitrogencooled cryostat, with the samples kept in vacuum $\left(10^{-7}\right.$ mbar). PL decay measurements were performed using mechanical modulation of the beam. The decay signals were recorded and averaged using a digitizing oscilloscope system. The total system response time was $30 \mu \mathrm{s}$. Photoluminescence excitation spectroscopy was performed using a Ti:sapphire laser which was tuned in the wavelength range $925-1030 \mathrm{~nm}$ at a fixed pump power of $10 \mathrm{~mW}$ at the sample. The Ti:sapphire laser was pumped using all lines of an Ar laser at a power of roughly $5 \mathrm{~W}$.

\section{RESULTS AND DISCUSSION}

\section{A. Optical activation of $\mathrm{Er}$ in $\mathrm{Si}$}

\section{1. $P L$ spectra and annealing behavior}

Figure 1 shows a PL spectrum (measured at $77 \mathrm{~K}$ ) of Er-implanted $\mathrm{Cz}-\mathrm{Si}\left(9 \times 10^{14} \mathrm{Er} / \mathrm{cm}^{2}\right)$ after SPE at $600^{\circ} \mathrm{C}$.

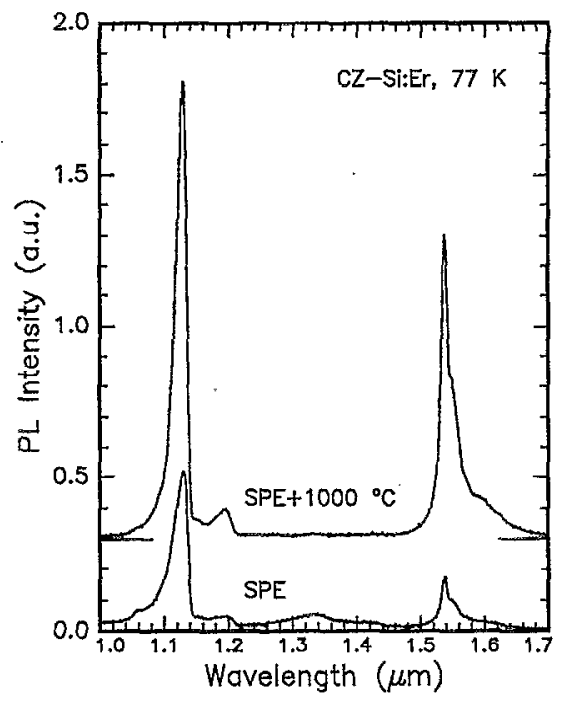

FIG. 1. Photoluminescence spectra taken at $77 \mathrm{~K}$ for Er-implanted Si $(250$ $\mathrm{keV}, 9 \times 10^{14} \mathrm{~cm}^{-2}$ ) after SPE recrystallization at $600^{\circ} \mathrm{C}$ (lower spectrum), and after subsequent thermal annealing at $1000^{\circ} \mathrm{C}$ for $15 \mathrm{~s}$ (upper spectrum). The upper spectrum was shifted vertically for clarity. The pump power at $514.5 \mathrm{~nm}$ was $160 \mathrm{~mW}$; the resolution $6 \mathrm{~nm}$.

The spectrum shows four clear features around 1.131, 1.20, 1.34, and $1.54 \mu \mathrm{m}$, respectively. The first two peaks correspond to phonon-assisted near-band-edge (BE) luminescence of $\mathrm{Si}^{28}$ The broad band around $1.3 \mu \mathrm{m}$ is very similar to defect bands found earlier for ion-damaged $\mathrm{Si}$ after annealing. ${ }^{28}$ The peak around $1.54 \mu \mathrm{m}$ represents the characteristic luminescence from $\mathrm{Er}^{3+}$ and originates from transitions between the first excited ${ }^{4} I_{13 / 2}$ manifold and the ${ }^{4} I_{15 / 2}$ ground manifold. A spectrum for the sample regrown by SPE and subsequently annealed at $1000^{\circ} \mathrm{C}$ for $15 \mathrm{~s}$ is also shown in Fig. 1. As can be seen, the defect band has now disappeared and both the Er and the band-edge luminescence have increased. PL decay measurements were also performed and show a slight nonexponential behavior. ${ }^{19}$ The typical 1/e time for both samples in Fig. 1 was $0.80 \pm 0.05 \mathrm{~ms}$.

The data in Fig. 1 show that the Er PL intensity can be increased fivefold by subsequent thermal annealing at $1000^{\circ} \mathrm{C}$. Anneals were also performed at other temperatures in the range $600-1300^{\circ} \mathrm{C}(15 \mathrm{~s})$ and it was found that annealing at $1000^{\circ} \mathrm{C}$ resulted in the optimum $\mathrm{Er}$ PL intensity at $1.54 \mu \mathrm{m}$. Figure 2 shows measurements of the Er PL peak intensity at $1.54 \mu \mathrm{m}$ as a function of annealing time at $1000^{\circ} \mathrm{C}$. The intensity after $0 \mathrm{~s}$ annealing corresponds to that of the sample after SPE (bottom curve in Fig. 1). As can be seen the optimum annealing time is $15 \mathrm{~s}$; longer annealing reduces the Er PL intensity. The BE PL intensity at $1.131 \mu \mathrm{m}$ is also indicated in Fig. 2. It shows a threefold increase after annealing for $15 \mathrm{~s}$ and also a decreasing trend for longer annealing times. The $\mathrm{Er} 1 / e$ PL lifetimes are also indicated in the figure. The lifetime increases from $0.75 \pm 0.05 \mathrm{~ms}$ for the sample after SPE, to $0.98 \pm 0.05 \mathrm{~ms}$ after subsequent annealing at $1000{ }^{\circ} \mathrm{C}$ for $5 \mathrm{~min}$. The lifetime of the $\mathrm{BE}$ luminescence was also measured, but could not be resolved within the $30 \mu \mathrm{m}$ time resolution of the system. Indeed, it is ex- 


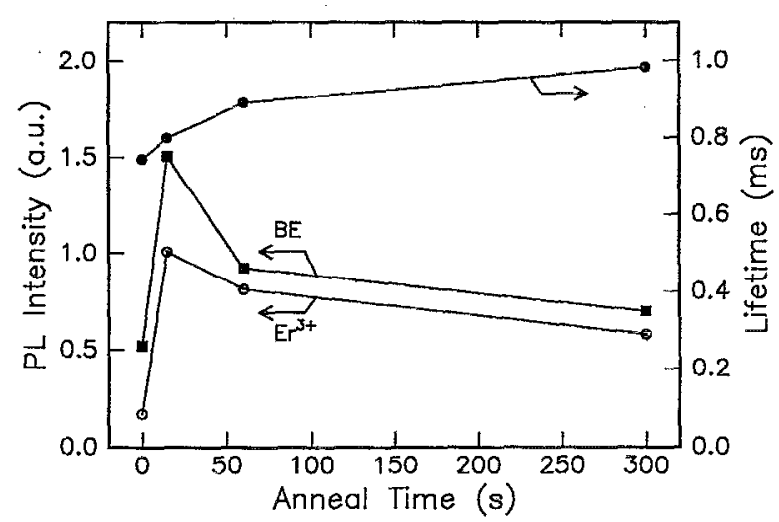

FIG. 2. Measurements at $77 \mathrm{~K}$ of the Er PL intensity at $1.54 \mu \mathrm{m}$, the $\mathrm{BE}$ luminescence at $1.131 \mu \mathrm{m}$, and the Er luminescence lifetime at $1.54 \mu \mathrm{m}$, all as a function of annealing time at $1000^{\circ} \mathrm{C}$. The samples were implanted with $250 \mathrm{keV} \mathrm{Er}$ at $9 \times 10^{14} \mathrm{~cm}^{-2}$ and recrystallized by SPE at $600^{\circ} \mathrm{C}$. The pump power at $514.5 \mathrm{~nm}$ was $160 \mathrm{~mW}$.

pected that the minority-carrier lifetime in ion implanted and doped crystal $\mathrm{Si}$ is much less than $30 \mu \mathrm{s}$.

\section{Er excitation}

Erbium may be excited in $\mathrm{Si}$ either by direct absorption or through a photocarrier-mediated process. To distinguish between the two effects, photoluminescence excitation spectroscopy was performed using a Ti:sapphire laser tuned at wavelengths in the range $925-1030 \mathrm{~nm}$. Note that the Si band-gap energy at $77 \mathrm{~K}$ corresponds to a wavelength of $1063 \mathrm{~nm}$. Figure 3 shows the $1.535 \mu \mathrm{m}$ luminescence intensity as a function of pump wavelength for the Er-implanted $\mathrm{Cz}$-Si sample (SPE $+1000^{\circ} \mathrm{C}$ ). The pump power was fixed at $10 \mathrm{~mW}$ at each wavelength and the data were taken at $77 \mathrm{~K}$. As can be seen the Er luminescence signal is a slightly monotonically decreasing function of pump wavelength (a

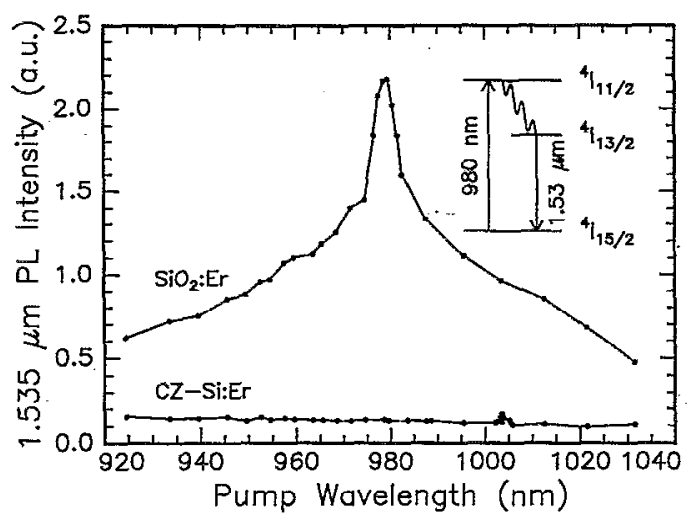

FIG. 3. Photoluminescence excitation spectrum of Er-implanted Cz-Si (250 $\left.\mathrm{keV}, 9 \times 10^{14} \mathrm{Er} / \mathrm{cm}^{2}+600^{\circ} \mathrm{C}, 15 \mathrm{~min}+1000^{\circ} \mathrm{C}, 15 \mathrm{~s}\right)$ at $77 \mathrm{~K}$, and of an Er-implanted $\mathrm{SiO}_{2}$ film $\left(500 \mathrm{keV}, 1.8 \times 10^{15} \mathrm{Er} / \mathrm{cm}^{2}+900^{\circ} \mathrm{C}, 30 \mathrm{~min}\right)$ at 77 $\mathrm{K}$. The PL intensity at $1.535 \mu \mathrm{m}$ is measured as a function of the pump wavelength. The pump power was $10 \mathrm{~mW}$. The inset shows the Er energylevel diagram. small feature is seen at $1003 \mathrm{~nm}$, which is not related to $\mathrm{Er}$, as the PL spectrum taken using this pump wavelength (not shown) does not show the typical spectral shape for $\mathrm{Er}^{3+}$ ).

For comparison, a PL excitation spectrum of an Erimplanted $\mathrm{SiO}_{2}$ film $\left(500 \mathrm{keV}, 1.7 \times 10^{15} \mathrm{Er} / \mathrm{cm}^{2}\right.$, annealed at $900^{\circ} \mathrm{C}$ ) is also shown, measured using the same pump power of $10 \mathrm{~mW}$. The peak in this spectrum corresponds to absorption at the ${ }^{4} I_{15 / 2} \rightarrow{ }^{4} I_{11 / 2}$ transition in $\mathrm{Er}^{3+}$. After excitation to this level, the ion first decays nonradiatively to the ${ }^{4} I_{13 / 2}$ level, whereupon it decays to the ground state by emission of a $1.535 \mu \mathrm{m}$ photon (see inset in Fig. 3). From the fact that the peak at $980 \mathrm{~nm}$ is not observed in the spectrum for $\mathrm{Er}$ doped $\mathrm{Si}$, we conclude that the luminescence from $\mathrm{Er}$ in $\mathrm{Si}$ is due to a photocarrier-mediated process, rather than to direct absorption.

\section{Discussion}

Knowing that luminescent $\mathrm{Er}$ is excited electrically, the annealing characteristics in Fig. 2 may be explained. The fact that the Er PL lifetime increases from $0.75 \pm 0.05$ to 0.98 $\pm 0.05 \mathrm{~ms}$ indicates that the luminescence efficiency increases by $30 \%$ on annealing. The much larger (fivefold) increase in Er PL intensity upon annealing for $15 \mathrm{~s}$ must then result from either an increase in the optically active $\mathrm{Er}$ fraction or an increase in excitation efficiency. The increased BE PL intensity after $15 \mathrm{~s}$ annealing reflects an increased minority-carrier lifetime, attributed to annealing of carrier recombination centers remaining after SPE. Indeed, the defect band around $1.36 \mu \mathrm{m}$ in the PL spectra of Fig. 1 has disappeared after annealing. As an increased carrier lifetime leads to a more efficient excitation of $\mathrm{Er}$, we conclude that the fivefold increase in Er PL after $15 \mathrm{~s}$ annealing is mainly due to the increased carrier lifetime. The decrease in BE PL for longer annealing times may result from activation of chemical impurities introduced or activated in the $\mathrm{Si}$ in the RTA process, which reduce the carrier lifetime.

\section{B. Maximum active Er concentration in $\mathrm{Cz}-\mathrm{Si}$}

\section{Er depth profiles}

There have been some earlier studies on the concentration dependence of the Er luminescence in ion implanted $\mathrm{Si}^{3,4,6}$ In these studies Er was directly implanted into $c$-Si at a wide range of fluences. As is well established, defect structures in ion-implanted $\mathrm{Si}$ are very fluence dependent, ranging from isolated point defects to amorphous layers. Comparing Er luminescence intensities in materials with such a broad range of microstructures is obviously very difficult, even after annealing, since the minority-carrier lifetimes will depend on the implantation fluence. In this way, the carrier density available for excitation of Er is sample dependent, and Er PL intensities cannot be compared directly. We have circumvented these problems by first preamorphizing a $\mathrm{Cz}-\mathrm{Si}$ surface layer with a $350 \mathrm{keV} \mathrm{Si}$ implant at $77 \mathrm{~K}$, and then implanting $250 \mathrm{keV}$ Er into the amorphous surface layer at fluences of $8 \times 10^{11}, 8 \times 10^{12}, 8 \times 10^{13}$, or $8 \times 10^{14} \mathrm{Er} / \mathrm{cm}^{2}$ (fluence, or areal density, is defined as the Er concentration in- 


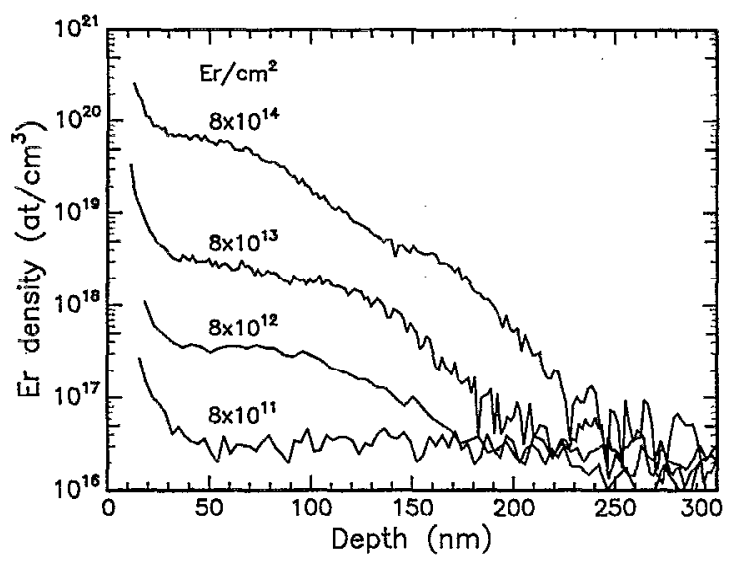

FIG. 4. SIMS Er depth profiles for four different samples. Cz-Si(100) was preamorphized using $350 \mathrm{keV} \mathrm{Si}$, and then implanted with $250 \mathrm{keV} \mathrm{Er}$ at $8 \times 10^{11}, 8 \times 10^{12}, 8 \times 10^{13}$, and $8 \times 10^{14} \mathrm{Fr} / \mathrm{cm}^{2}$. The samples were then recrystallized at $600^{\circ} \mathrm{C}$ and subsequently annealed at $1000^{\circ} \mathrm{C}$ for $15 \mathrm{~s}$.

tegrated over the implanted depth). The Er-doped $a$-Si layers were then all recrystallized by SPE at $600^{\circ} \mathrm{C}$ for $15 \mathrm{~min}$ and subsequently annealed at $1000^{\circ} \mathrm{C}$ for $15 \mathrm{~s}$.

Figure 4 shows SIMS measurements of the Er depth profiles for the four different samples after this treatment. The trapped Er concentrations range from $3 \times 10^{16}$ to $7 \times 10^{19}$ $\mathrm{Er} / \mathrm{cm}^{3}$. The profile for the lowest fluence $\left(8 \times 10^{11} \mathrm{Er} / \mathrm{cm}^{2}\right)$ is limited by the sensitivity of SIMS. The profiles for the two intermediate fiuences are identical in shape, with the relative heights proportional to the implanted Er fluences. The shape of the profile for the highest Er fluence $\left(8 \times 10^{14} \mathrm{Er} / \mathrm{cm}^{2}\right)$ shows an enhanced trapped concentration between 30 and $100 \mathrm{~nm}$ depth, when compared to the shape for the samples with the lower concentrations. This is in agreement with our model of $\mathrm{Er}$ segregation and trapping at the moving amorphous-crystalline interface during SPE, in which it is postulated that defects in the amorphous Si near the moving interface act as traps for segregating Er. ${ }^{18}$ According to this model, the relative amount of trapping in the crystal should increase when all traps on the amorphous side of the moving interface become filled at high Er concentrations, as is indeed observed in Fig. 4 for the highest fluence. All SIMS profiles show a peak near the surface corresponding to $\mathrm{Er}$ that has segregated out.

\section{2. $P L$ versus fluence}

In Fig. 5, the Er PL peak intensity at $1.54 \mu \mathrm{m}$, measured at $77 \mathrm{~K}$, is shown as a function of pump power for the four different samples. A rapid initial increase is seen for all samples, followed by a leveling off for higher pump powers. At a given pump power, the intensity increases with Er fluence for the three lowest fluences, and then decreases again for the sample implanted with $8 \times 10^{14} \mathrm{Er} / \mathrm{cm}^{2}$. The leveling off at high pump powers may be explained by the fact that a large fraction of Er becomes excited as the pump power (i.e., steady-state electrical carrier concentration) is increased. It is important to note that the shape of the four curves in Fig. 5 is

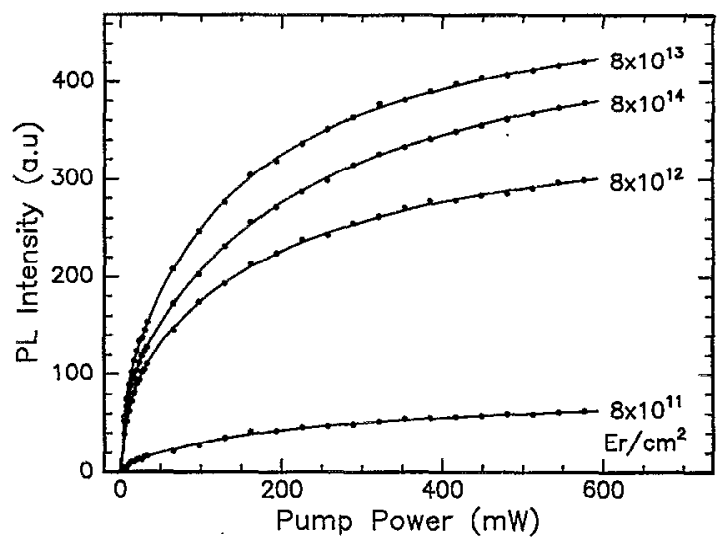

FIG. 5. Photoluminescence intensity at $1.54 \mu \mathrm{m}$ as a function of pump power at $514.5 \mathrm{~nm}$, measured at $77 \mathrm{~K}$, for the samples in Fig. 4. The drawn lines are guides for the eye.

identical, apart from a vertical scaling parameter which depends on the Er fluence. This implies that the recombination of electrical carriers is not dominated by the Er ions themselves, but rather by other structural defects of which the concentration is independent of Er concentration. The similarity in the shapes of the four curves in Fig. 5 implies that when comparing the PL intensity for different Er concentrations (Fig. 6), this comparison may be done at any pump power.

In Fig. 6 the PL intensity at $77 \mathrm{~K}$, measured at a pump power of $160 \mathrm{~mW}$, is plotted as a function of Er fluence for the four different samples. For the two low-fluence implants the PL intensity increases nearly linearly with fluence. Above $10^{13} \mathrm{Er} / \mathrm{cm}^{2}$ the intensity levels off and does not increase much further. A small decrease in intensity is seen for the sample with $8 \times 10^{14} \mathrm{Er} / \mathrm{cm}^{2}$. Measurements of the $\mathrm{Er} \mathrm{PL}$ lifetime as a function of Er fluence are also included in Fig. 6. The $1 / e$ lifetime decreases with $\mathrm{Er}$ concentration, from $1.14 \pm 0.05 \mathrm{~ms}$ for the lowest fluences to $0.74 \pm 0.05 \mathrm{~ms}$ for

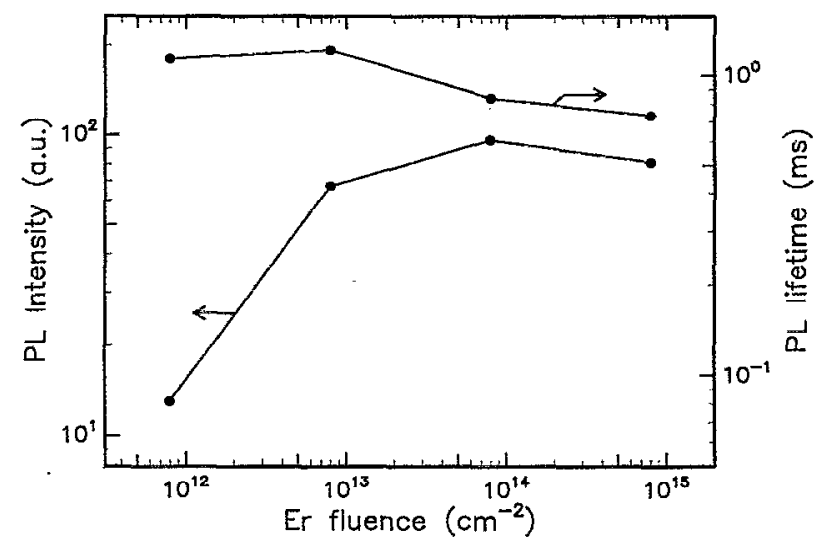

FIG. 6. Photoluminescence intensity and lifetime at $1.54 \mu \mathrm{m}$ as a function of Er fluence, measured at $77 \mathrm{~K}$, for the samples in Fig. 4. The pump power at $514.5 \mathrm{~nm}$ was $160 \mathrm{~mW}$. 


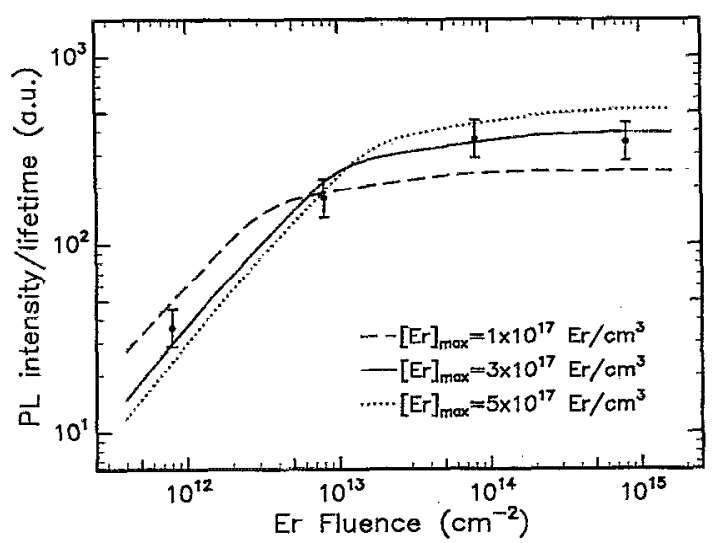

FIG. 7. Photoluminescence intensity divided by the lifetime (data from Fig. 6), which is a relative measure of the total areal density of optically active Er, plotted as a function of Er implantation fluence. The drawn lines are calculated from the SIMS profiles, using a model in which it was assumed that there is a maximum Er concentration that can be activated in Cz-Si. Curves are shown for $[\mathrm{Er}]_{\max }=1 \times 10^{17}, 3 \times 10^{17}$, or $5 \times 10^{17} \mathrm{Er} / \mathrm{cm}^{3}$. The best agreement is obtained for $[\mathrm{Er}]_{\max }=(3 \pm 1) \times 10^{17} \mathrm{Er} / \mathrm{cm}^{3}$.

the highest fluence. The BE PL intensity was the same for all samples indicating that the minority-carrier lifetime was the same in each sample. Therefore, the carrier density available for excitation of $\mathrm{Er}$ was the same in all samples, enabling similar pump conditions for the Er. The fact that the minority-carrier density under steady-state pumping is similar for all Er concentrations again indicates that the Er ions themselves are not the dominant recombination centers for electrical carriers. This implies that only a small fraction of the photogenerated carriers is actually used to excite Er ions, and therefore the internal quantum efficiency for excitation is rather low.

Assuming that the Er PL lifetime is a measure for the luminescence efficiency, the PL intensity data can be corrected in order to obtain a relative measure of the optically active Er fluence. This is shown in Fig. 7, in which the PL intensity data from Fig. 6 are divided by the lifetime for each sample.

\section{Concentration limit model}

The data in Fig. 7 clearly show a saturation in optically active Er fluence above $10^{13} \mathrm{Er} / \mathrm{cm}^{2}$. The data can be analyzed by assuming that there is a maximum $\mathrm{Er}$ concentration that can be optically activated $[\mathrm{Er}]_{\max }$. Any Er trapped at concentrations above $[\mathrm{Er}]_{\max }$ would then remain inactive. For each SIMS profile in Fig. 4 we can then determine the total areal density of optically active Er by calculating the integrated areal density of Er below $[\mathrm{Er}]_{\max }$. This areal density should then be proportional to the Er PL data in Fig. 7.

Two problems arise if this integration is done with the data in Fig. 4. First, it results in only four data points, rather than a continuous calculation as a function of fluence. Second, the data for the lowest fluence are inaccurate because of the SIMS sensitivity. To avoid these problems we have taken the SIMS profile for the $8 \times 10^{13} \mathrm{Er} / \mathrm{cm}^{2}$ implant as a representative depth profile, and scaled it with a factor propor- tional to the fluence, in order to model the $\mathrm{Er}$ profile for any fluence in the range $4 \times 10^{11}-2 \times 10^{15} \mathrm{Er} / \mathrm{cm}^{2}$. For a certain value of $[\mathrm{Er}]_{\max }$ we then calculated for each fluence the integrated areal density of $\mathrm{Er}$ below $[\mathrm{Er}]_{\max }$. The continuous lines in Fig. 7 are results of this procedure, using three different values for $[\mathrm{Er}]_{\max }$. As the PL intensity is only measured in relative units, each curve was scaled in the vertical direction to obtain best agreement with the data. As can be seen, the best fit is obtained using $[\mathrm{Er}]_{\max }=(3 \pm 1) \times 10^{17}$ $\mathrm{Er} / \mathrm{cm}^{3}$. This implies that, for example, for a $8 \times 10^{14} \mathrm{Er} / \mathrm{cm}^{2}$ implant (top curve in Fig. 4, with up to $7 \times 10^{19} \mathrm{Er} / \mathrm{cm}^{3}$ trapped in the crystal) only $6 \times 10^{12} \mathrm{Er} / \mathrm{cm}^{2}$, i.e., less than $1 \%$ of the implanted fluence, is optically active.

\section{Er configuration in $\mathrm{Si}$}

Previous experiments have shown that the addition of oxygen to Er-implanted $\mathrm{Cz}-\mathrm{Si}$ can enhance the $\mathrm{Er} \mathrm{PL}$ intensity. ${ }^{3,4,9}$ The addition of $\mathrm{O}$ increases the luminescent $\mathrm{Er}$ concentration and reduces the PL quenching at elevated temperatures. $^{19}$ Extended $\mathrm{x}$-ray-absorption-edge finestructure spectroscopy (EXAFS) measurements have shown that Er forms clusters with $\mathrm{O}$. It was concluded that $\mathrm{Er}$ in this cluster was coordinated by roughly $4-6 \mathrm{O}$ atoms. ${ }^{14}$

Using this coordination number and the known $\mathrm{O}$ content in our $\mathrm{Cz}$ wafer of $(1.7 \pm 0.5) \times 10^{18} \mathrm{O} / \mathrm{cm}^{3}$, and assuming that in the Er-doped region all $\mathrm{Er}$ is bound to oxygen, we can derive a separate estimate of $[\mathrm{Er}]_{\max }: 2-6 \times 10^{17} \mathrm{Er} / \mathrm{cm}^{3}$. This number is in good agreement with the number found above from Fig. 7. As these Er-O complex seem to form so readily, we can consider $\mathrm{Er}$ as a microscopic getter in $\mathrm{Si}$ which binds with any $\mathrm{O}$ within a typical diffusion distance. This then has an important conscquence for the definition of the solubility of $\mathrm{Er}$ in $\mathrm{Si}$. By analogy with the transition metals the solubility of $\mathrm{Er}$ in pure single-crystal $\mathrm{Si}$ would likely be relatively low $\left.\left(10^{14}-10^{16} \mathrm{Er} / \mathrm{cm}^{3}\right)\right)^{29}$ Other measurements ${ }^{11}$ have suggested that the solubility in $\mathrm{Cz}-\mathrm{Si}$ is around $1 \times 10^{18} \mathrm{Er} / \mathrm{cm}^{3}$. Given the strong tendency for $\mathrm{Er}$ to bind with $\mathrm{O}$, we suggest that in $\mathrm{Cz}-\mathrm{Si}$ with $(1.7 \pm 0.5) \times 10^{18}$ $\mathrm{O} / \mathrm{cm}^{3}$, oxygen enhances the effective solubility of $\mathrm{Er}$ to at least $[\mathrm{Er}]_{\max }=3 \times 10^{17} \mathrm{Er} / \mathrm{cm}^{3}$, i.e., no Er-related precipitates will be observed up to this Er concentration in Cz-Si. Indecd, this is in agreement with transmission electron microscopy data. ${ }^{11,13}$ Also, this solubility model explains the observation that if high $\mathrm{Er}$ and $\mathrm{O}$ concentrations are co-implanted in such a ratio that not enough $\mathrm{O}$ is available to bind all $\mathrm{Er}$ in $\mathrm{Er}-\mathrm{O}$ clusters, Er-related precipitates are formed. ${ }^{9}$ From the annealing studies in Fig. 2 it follows that the Er-O clusters are stable up to at least $1000^{\circ} \mathrm{C}$.

It is interesting to compare our data on the optical activation of $\mathrm{Er}$ in $\mathrm{Cz}$-Si with those on electrical activation. $\mathrm{Er}$ exhibits donor behavior in $\mathrm{Si}$ and it was found ${ }^{7}$ that the maximum carrier concentration in $\mathrm{Cz}-\mathrm{Si}$ was reached for an Er concentration of $(4-7) \times 10^{17} \mathrm{Er} / \mathrm{cm}^{3}$, very similar to the value found in the present article for optical activation. These data suggest that the optically and electrically active Er sites in Si may be the same. Such a correlation between optically and electrically active sites also follows from $O$ codoping experiments which showed that $O$ enhances both the optically and electrically active fraction. ${ }^{7,9}$ 
More measurements will be required to determine the nature of the large optically (and electrically) inactive fraction of $\mathrm{Er}$ in $\mathrm{Cz}-\mathrm{Si}$. Preliminary x-ray-absorption spectroscopy measurements on samples in which only 1 at. \% $\mathrm{Er}$ is optically active, show that all $\mathrm{Er}$ is in the trivalent charge state. ${ }^{30}$ This suggests that the inactive Er has either a very small luminescence quantum efficiency (short luminescence lifetime) or a small excitation efficiency, and therefore does not contribute to the PL spectra.

\section{Quantum efficiency}

Using the data in Fig. 3 we can make a rough estimate of the internal quantum efficiency for carrier-mediated excitation of $\mathrm{Er}$ in Si. We compare the PL intensities for the Erdoped $\mathrm{Si}$ and $\mathrm{SiO}_{2}$ samples, at a pump wavelength of 980 $\mathrm{nm}$. At this wavelength, the absorption cross section $\sigma_{a}$ for optical absorption of $\mathrm{Er}$ in $\mathrm{SiO}_{2}$ is known and the PL intensity from $\mathrm{Er}$ in $\mathrm{SiO}_{2}$ is given by

$$
I_{\text {opt }}=\frac{I_{\text {pump }}}{h \nu_{\text {pump }}} \sigma_{a} \phi_{0} c_{0},
$$

with $I_{\text {pump }}$ the pump intensity, $h$ Planck's constant, $v_{\text {pump }}$ the pump frequency, $\phi_{0}$ the Er fluence in the oxide, and $c_{0}$ a correction factor taking into account reflection and refraction of the pump beam as well as the collection efficiency. For electrical excitation of $\mathrm{Er}$ in $\mathrm{Si}$ we can write for the PL intensity

$$
I_{\mathrm{el}}=\frac{I_{\text {pump }}}{h \nu_{\text {pump }}} Q c_{s},
$$

with $Q$ the quantun efficiency, defined as the fraction of photogenerated electron-hole pairs that recombine by transferring energy to an $\mathrm{Er}$ ion, and $c_{s}$ the correction factor for Si. Combining Eqs. (1) and (2) we find

$$
\frac{I_{\mathrm{el}}}{I_{\mathrm{opt}}}=\frac{c_{s} Q}{c_{0} \sigma_{a} \phi_{0}} \text {. }
$$

From Fig. 3 we determine the ratio $I_{\mathrm{el}} / I_{\mathrm{opt}}=0.06$. Using a recent measurement of $\sigma_{a}\left(2 \times 10^{-21} \mathrm{~cm}^{2}\right),^{31}$ the known fluence $\phi_{0}$, and estimates for $c$, we can solve the only unknown parameter $Q=3 \times 10^{-6}$. Note that this calculation assumes that all photogenerated carriers recombine in the Er-doped region. In reality, a significant fraction of the carriers will recombine outside this region. The number of $3 \times 10^{-6}$ is, therefore, a lower limit.

This value for the quantum efficiency is a small number, and indicates that the main carrier recombination route is not through Er ions. This follows also implicitly from the observation that all samples in Fig. 6, with a large range of Er concentrations, had the same band-edge luminescence and, therefore, carrier lifetime. It also follows from the fact that the pump power dependence in Fig. 5 is the same for all $\mathrm{Er}$ concentrations. Clearly, the structural defects remaining after SPE, such as for example end-of-range dislocations, dominate the electrical characteristics in these samples. Future work should focus on reduction or passivation of these defects. The quantum efficiency can be further increased if the $\mathrm{Er}$ active fraction is increased. By co-implanting additional oxygen, and by increasing the Er depth using $\mathrm{MeV}$ implantation energies, we expect that the quantum efficiency can be improved to $10^{-2}-10^{-3}$.

\section{CONCLUSION}

In conclusion, we have addressed several requirements for the attainment of efficient luminescence of $\mathrm{Er}$ in $\mathrm{Si}$, as follows.

(1) High Er concentrations, up to $7 \times 10^{19} \mathrm{Er} / \mathrm{cm}^{3}$, were incorporated by SPE crystallization of an implantationamorphized Er-doped Si surface layer at $600^{\circ} \mathrm{C}$.

(2) A fraction of the Er is optically active after SPE and the photoluminescence intensity at $1.54 \mu \mathrm{m}$ can be further optimized by subsequent thermal annealing at $1000^{\circ} \mathrm{C}$ for $15 \mathrm{~s}$. In Cz-grown Si the optically active Er concentration is limited to $(3 \pm 1) \times 10^{17} \mathrm{Er} / \mathrm{cm}^{3}$.

(3) The luminescence lifetime at $77 \mathrm{~K}$ is around $1 \mathrm{~ms}$. This is in the same order of magnitude as the radiative lifetime of Er in many solids, and therefore the luminèscence efficiency at $77 \mathrm{~K}$ is high. Due to strong temperature quenching, no luminescence is observed at room temperalure; However, as we have shown in previous work $^{19}$ the quenching can be reduced by the addition of impurities, such as oxygen.

(4) $\mathrm{Er}$ is excited through photocarriers, and therefore the photocarrier lifetime is an important parameter determining the luminescence intensity. This should be taken into account when impurities are co-implanted to enhance the active Er concentration, as such impurities and the structural defects associated with their incorporation will decrease the minority-carrier lifetime. The internal quantum efficiency for excitation of Er is larger than $3 \times 10^{-6}$, and can be improved by increasing the optically active Er concentration, for example by co-implantation of oxygen and distribution of the Er over larger depths.

\section{ACKNOWLEDGMENTS}

This work is part of the research program of the Foundation for Fundamental Research on Matter (FOM) and was made possible by financial support from the Dutch Organization for the Advancemeñt of Pure Research (NWO), the Netherlands Technology Foundation (STW), and the IC Technology Program (IOP Electro-Optics) of the Ministry of Economic Affairs. R.S. acknowledges financial support from CSIC, Spain.

${ }^{1}$ H. Ennen, J. Schneider, G. Pomrenke, and A. Axmann, Appl. Phys. Lett. 43, 943 (1983).

${ }^{2}$ H. Ennen, G. Pomrenke, A. Axman, K. Eisele, W. Haydl, and J. Schneider, Appl. Phys. Lett. 46, 381 (1985).

${ }^{3}$ P. N. Favennec, H. l'Haridon, D. Moutonnet, M. Salvi, and M. Gauneau, Jpn. J. Appl. Phys. 29, L524 (1990).

${ }^{4}$ J. Michel, J. L. Benton, R. F. Ferrante, D. C. Jacobson, D. J. Eaglesham, E. A. Fitzgerald, Y.-H. Xie, J. M. Poate, and L. C. Kimerling, J. Appl. Phys. 70, 2672 (1991).

${ }^{5}$ Y. S. Tang, K. C. Heasman, W. P. Gillin, and B. J. Sealy, Appl. Phys. Lett. 55, 432 (1989).

${ }^{6}$ D. Moutonnet, H. I'Haridon, P. N. Favennec, M. Sali, M. Gauneau, F. Arnaud d'Avitaya, and J. Chroboczek, Mater. Sci. Eng. B 4, 75 (1989).

${ }^{7}$ J. L. Benton, J. Michel, L. C. Kimerling, D. C. Jacobson, Y. -H. Xie, D. J. 
Eaglesham, E. A. Fitzgerald, and J. M. Poate, J. Appl. Phys. 70, 2667 (1991).

${ }^{8}$ F. P. Widdershoven and J. P. M. Naus, Mater. Sci. Eng. B 4, 71 (1989).

${ }^{9}$ F. Priolo, S. Coffa, G. Franzó, C. Spinella, A. Carnera, and V. Bellani, J. Appl. Phys. 74, 4936 (1993).

${ }^{10}$ W. P. Gillin, J.-P. Zhang, and B. J. Sealy, Solid State Commun. 77, 907 (1991).

${ }^{11}$ D. J. Eaglesham, J. Michel, E. A. Fitzgerald, D. C. Jacobson, J. M. Poate, J. L. Benton, A. Polman, Y.-H. Xie, and L. C. Kimerling, Appl. Phys. Lett. 58, 2797 (1991).

${ }^{12}$ A. Polman, J. S. Custer, E. Snoeks, and G. N. van den Hoven, Nucl. Instrum. Methods B 80/81, 653 (1993).

${ }^{13}$ A. Polman, J. S. Custer, E. Snoeks, and G. N. van den Hoven, Appl. Phys. Lett. 62, 507 (1993).

${ }^{14}$ D. L. Adler, D. C. Jacouson, D. J. Eaglesham, M. A. Marcus, J. L. Benton, J. M. Poate, and P. H. Citrin, Appl. Phys. Lett. 61, 2181 (1992).

${ }^{15}$ J. S. Custer, A. Polman, E. Snoeks, and G. N. van den Hoven, Mater. Res. Soc. Proc. 301, 101 (1993).

${ }^{16}$ M. Efeoglu et al. Semicond. Sci. Technol. 8, 238 (1993).

${ }^{17}$ Y. S. Tang, J.-P. Zhang, K. C. Heasman, and B. J. Sealy, Solid State Commun. 72, 991 (1989).

${ }^{18}$ J. S. Custer, A. Polman, and H. M. van Pinxteren, J. Appl. Phys. 75, 2809 (1994).
${ }^{19}$ S. Coffa, G. Franzò, F. Priolo, A. Polman, and R. Serna, Phys. Rev. B 49, 16313 (1994).

${ }^{20}$ S. Lombardo, S. U. Campisano, G. N. van den Hoven, A. Cacciato, and A. Polman, Appl. Phys. Lett. 63, 1942 (1993).

${ }^{21}$ G. N. van den Hoven, A. Polman, S. Lombardo, and S. U. Campisano (unpublished).

${ }^{22}$ R. Serna, E. Snoeks, G. N. van den Hoven, and A. Polman, J. Appl. Phys. 75, 2644 (1994).

${ }^{23}$ F. Y. G. Ren, J. Michel, Q. Sun-Paduano, B. Zheng, H. Kitagawa, D. C. Jacobson, J. M. Poate, and L. C. Kimerling, Mater. Res. Soc. Proc. 301, 87 (1993).

${ }^{24}$ G. Franzò, F. Priolo, S. Coffa, A. Polman, and A. Carnera, Appl. Phys. Lett. 64, 2235 (1994).

${ }^{25}$ S. Lombardo, S. U. Campisano, G. N. van den Hoven, and A. Polman (unpublished).

${ }^{26}$ R. G. Wilson, F. A. Stevie, and C. W. Magee, Secondary Ion Mass Spectrometry (Wiley, New York, 1989).

${ }^{27}$ G. E. Jellison and F. A. Modine, J. Appl. Phys. 53, 3745 (1982).

${ }^{28}$ G. Davies, Phys. Rep. 176, 83 (1989).

${ }^{29}$ F. A. Trumbore, Bell Syst. Tech. J. 39, 205 (1960).

${ }^{30} \mathrm{~J}$. B. Goedkoop and A. Polman (unpublished).

${ }^{31}$ G. N. van den Hoven and A. Polman (unpublished). 